\title{
Decrease of Thymic Hormone Serum Level in Cockayne Syndrome
}

\author{
ALBERT BENSMAN, ${ }^{(16)}$ MIREILLE DARDENNE, JEAN-FRANÇOIS BACH, JÉRÔME VALLETEAU DE \\ MOUILLAC, AND GERAUD LASFARGUES
}

Chaire D'Hygiène et Clinique de la Première Enfance, Hopital Trousseau, Paris-Unité Inserm U 25, Hopital Necker, Paris and Service de Pédiatrie, Hôpital Ambroise Paré, Boulogne, France

\begin{abstract}
Summary
Previous reports concerning children with Cockayne syndrome had described decreased $T$ cell proliferative responses and renal anomalies which could be associated with immunologic disturbances. Herein, the thymic function was evaluated by measuring the serum level of thymic hormone. This serum level was found to be undetectable or decreased in seven cases of Cockayne syndrome. Active serum concentrations varied between 0 and 1/8, whereas normal children of the same age show activity in the range between $1 / 16$ and $1 / 64$. In contrast, $T$ cell function, explored by phytohemagglutinin and Concavalin $A$ responses, and mixed lymphocyte cultures was normal. Whether or not this premature sign of immunological aging is primary or secondary to other manifestations of the syndrome is still difficult to assess.
\end{abstract}

\section{Speculation}

The discrepancy between low levels of thymic hormone found in seven cases of Cockayne syndrome which represents a biologic sign of aging, and normal $T$ cell function, is still unclear: we can suppose that the number of long-lived $T$ cells is sufficient to provide normal $T$ cell responses after decrease of thymic production.

The role of decreased thymic hormone level in the etiopathogenesis of the disease is difficult to evaluate: this decrease could be either responsible for clinical manifestations of the disease or only secondary to a more fundamental disorder.

The Cockayne syndrome is a rare disease, characterized by cachectic dwarfism, major involvement of the central nervous system, morphological anomalies, deafness, retinal pigmentation and premature senility $(6,13)$. It is not known whether these features of premature aging are associated with biologic manifestations of aging, in particular with the immunologic consequences of thymic involution. The decrease of thymic hormone level is well documented in aging mice and humans $(1,2)$. We report here an evaluation of the serum level of thymic hormone in seven cases of Cockayne syndrome.

\section{MATERIALS AND METHODS}

Seven children were investigated (Table 1): four males and three females, aged 2 to 17 years. Diagnosis of Cockayne syndrome was established by the following clinical and laboratory signs. (1) Family prevalence: the seven children belonged to four different families. Cases 1, 2 and 5, 6, 7 were siblings. (2) Characteristic morphologic anomalies: major microcephaly, thin and narrow face, frontal prominence, and loss of subcutaneous fat. Such abnormalities give the children the aspect of premature aging (Fig. 1). (3) Dwarfism: growth was studied in detail in three children. Growth rate was normal for the first 12 to 18 months, and then suddenly decreased (Fig. 2). (4) Mental retardation in all cases. (5) Photosensitivity and cataract in one case (case 3). (6) No signs of renal, digestive, or tndocrine abnormalities were found. There was no retinal pigmentation or deafness. (7) Some bone abnormalities were noted in all cases: microcephaly, posterior tapering of the vertebral bodies, small square-shaped steep iliac angles, coxa valga.

Only in the oldest children were other anomalies observed: basal ganglia calcifications (case 1), slender clavicles and ribs, slender diaphyses of the long bones, bulky metaphyses and epiphyses (cases 1, 3, 4,5), ivory epiphyses of the phalanges of hands and dense phalanged epiphysae (cases 1 and 5). The nutritional status of these children was within normal limits. None was undergoing any form of treatment at the time of investigation.

\section{IMMUNOLOGICAL STUDIES}

Immunological studies were performed in six cases. Organspecific autoantibodies were studied by immunofluorescence. Evaluation of anti-DNA antibodies was performed using the Farr test (11). Lymphocyte response to Concanavalin A (Con A) and to phytohemagglutinin (PHA) was performed by using a microtechnique with Ficoll-purified lymphocytes. DNA synthesis was evaluated by the uptake of tritiated thymidine. Mixed lymphocyte reactions were done according to the same methodology. Adenosine Desaminase determination was performed according to the method described by Cartier and Hamet (5).

\section{THYMIC HORMONE DETERMINATION}

Serum level of thymic hormone was studied using a rosette assay previously described (2). In brief, the assay is based on the capacity of the thymic hormone to induce the appearance of sensitivity to antitheta serum (ABS) or azathioprine $(\mathrm{Az})$ on spleen cells of adult thymectomized (ATx) mice that are resistant to these inhibitors. The hormone concentration is expressed as maximal active dilution of serum. Converging data have shown that the factor detected by this assay is a nonapeptide produced by the

Table 1. Age, weight, size, and level of circulating thymic hormone in seven cases of Cockayne syndrome

\begin{tabular}{|c|c|c|c|c|c|c|}
\hline \multirow[b]{2}{*}{ Case } & \multirow[b]{2}{*}{ Sex } & \multirow[b]{2}{*}{$\begin{array}{c}\text { Age } \\
\text { (years) }\end{array}$} & \multirow[b]{2}{*}{$\begin{array}{r}\mathrm{Wt} \\
(\mathrm{kg})\end{array}$} & \multirow[b]{2}{*}{$\begin{array}{l}\text { Size } \\
(\mathrm{cm})\end{array}$} & \multicolumn{2}{|c|}{$\begin{array}{c}\text { Level of circulating } \\
\text { thymic hormone }\end{array}$} \\
\hline & & & & & Patients & $\begin{array}{c}\text { Normal } \\
\text { subjects } \\
\text { of same } \\
\text { age }\end{array}$ \\
\hline 1 & $\mathrm{~F}$ & 17 & 13 & 98 & 0 & $1 / 16$ \\
\hline 2 & $\mathbf{M}$ & $56 / 12$ & 10.6 & 87.5 & $1 / 8$ & $1 / 64$ \\
\hline 3 & $\mathrm{~F}$ & 8 & 9.2 & 84 & $1 / 4$ & $1 / 32$ \\
\hline 4 & $\mathbf{M}$ & $88 / 12$ & 14.5 & 75 & $1 / 4$ & $1 / 32$ \\
\hline 5 & $\mathrm{M}$ & $83 / 12$ & 10.4 & 86 & $1 / 4$ & $1 / 64$ \\
\hline 6 & $\mathrm{~F}$ & $23 / 12$ & 8.5 & 75 & $1 / 2$ & $1 / 64$ \\
\hline 7 & $\mathbf{M}$ & $44 / 12$ & 9.2 & 83 & $1 / 2$ & $1 / 64$ \\
\hline
\end{tabular}




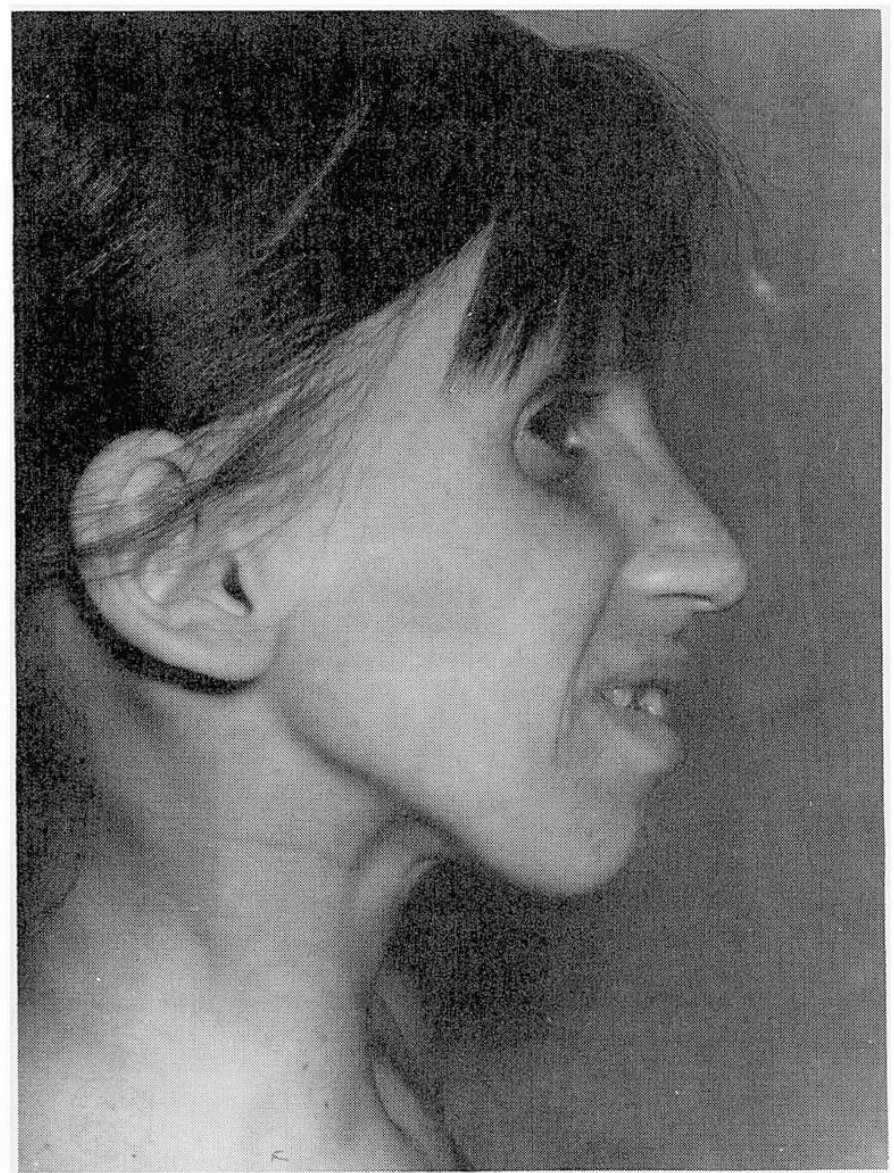

Fig. 1. Photograph of a patient with Cockayne syndrome (case 1).

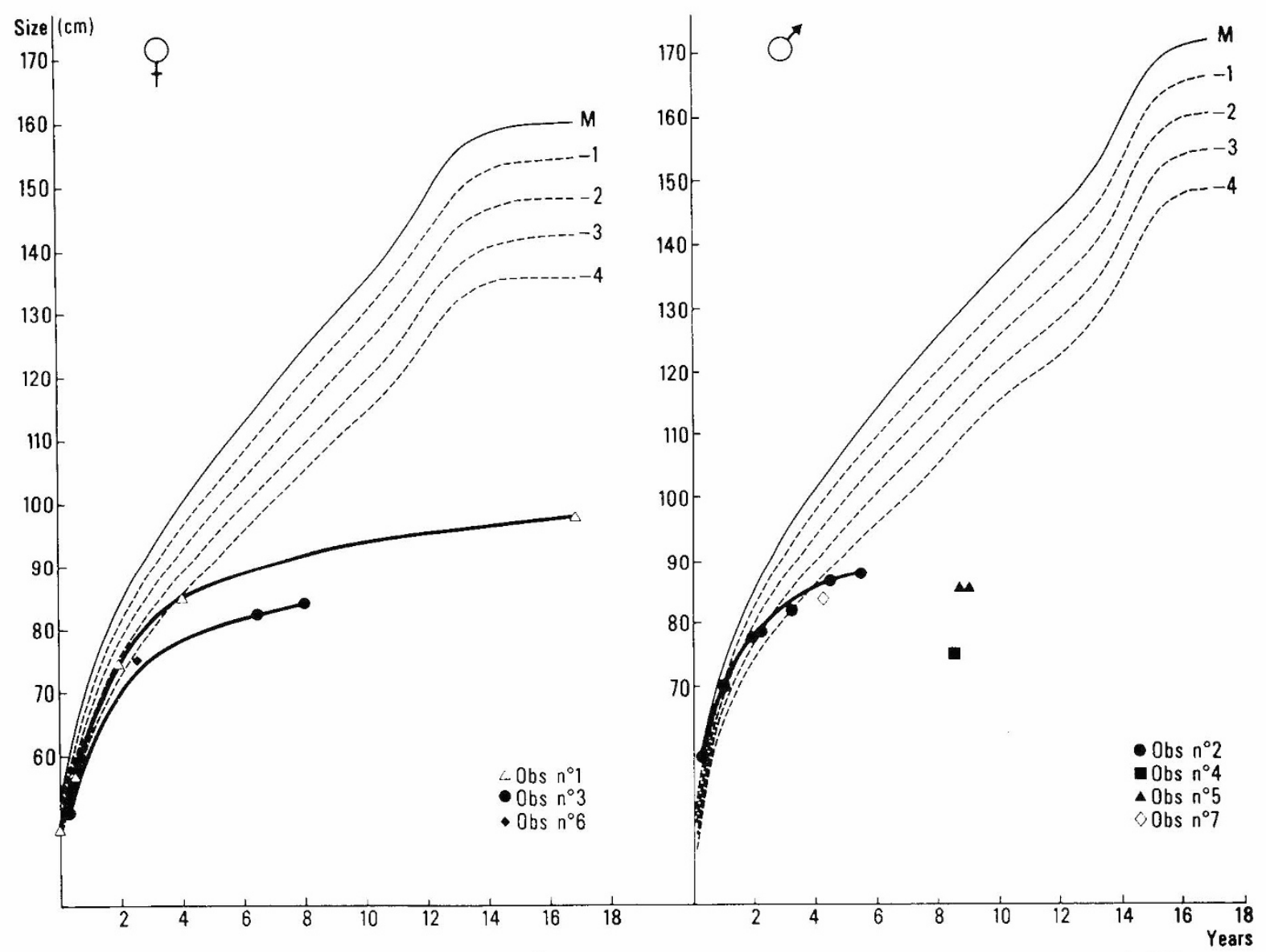

Fig. 2. Growth rates observed in children with Cockayne syndrome compared with the growth rates of normal children. thymus (3) (it disappears after thymectomy, is found in thymic extracts, and an antiserum against the synthetic hormone localizes selectively in the thymic epithelium). The identity of the factor under study was investigated further, in order to confirm the specificity of the assay and to eliminate the possibility that a factor might be present in patients with Cockayne syndrome, influencing rosette formation. Sera from Cockayne syndrome patients were incubated with normal serum of young control children and the mixture was tested again in the rosette assay for circulating thymic factor (FTS) determination.

\section{RESULTS}

The serum level of thymic hormone was found to be negative or decreased when compared with normal children of the same age in the seven cases studied (Table 1). Active serum concentrations varied between 0 and $1 / 8$, whereas normal children of the same age show activity in the range between $1 / 16$ and $1 / 64$ (1).

The absence of nonspecific products with inhibitory effects on the FTS level determination was confirmed by serum incubation experiments. The incubation of sera from Cockayne syndrome patients with normal high level sera from control subjects did not modify the FTS levels allowing us to concede to the specificity of the results found in the patients investigated. In all cases studied the lymphocyte response to PHA, Con A, and allogeneic cells was normal. In these cases the autoantibodies were investigated; no antibody was found (Coombs' test, antileukocyte, platelet, adrenal, epidermia, striated muscle, nuclear and DNA antibodies). Adenosine deaminase (ADA) levels were found to be within the normal range ( $494 \pm 62 \mathrm{nmole}$ for $1 \mathrm{ml}$ of red cells/min) in the six cases investigated.

\section{DISCUSSION}

The clinical aspect of premature senility found in children with Cockayne syndrome is associated with a biologic manifestation of 
aging - decrease in serum level of thymic hormone. This result is reminiscent of the necropsy finding by Rigss and Seifert (12) of a major thymic atrophy in a 7-year-old boy with Cockayne syndrome, although such data should be interpreted with caution because of the possibility of nonspecific involution of the thymus in agonal stages.

$T$ cell function and presence of autoantibodies have been studied in six of these cases, but results of these investigations were normal. These data are at variance with the report by Lafforet and Dupuy (9) on three children with Cockayne syndrome, showing a significant decrease in the lymphocyte proliferative response to PHA. One should note that the renal anomalies described by Ohno and Hirooka (10) and by Riggs and Seifert (12) could be associated with immunological disturbances. In addition, children with Cockayne syndrome show an abnormal incidence of infections $(8,9,14)$.

The discrepancy between low levels of thymic hormone and normal or subnormal $\mathrm{T}$ cell function may be explained by the normal production of thymic hormone probably present in the first month of life. It is probable that a sufficient number of longlived $T$ cells is produced during this period to provide normal $T$ cell responses, when thymic function has ceased. In our experience, the earliest age when thymic hormone levels have been measured (and found to be decreased) is 2 years.

The mechanism of the decrease in thymic hormone level found in Cockayne syndrome has not been definitively determined. It is probably that, as in aging mice (4), the major fact is a cessation of thymic hormone production. One cannot exclude, however, that circulating inhibitory factor are also involved as shown in aging mice (4).

The links between thymus anomalies, as revealed by the decrease in thymic hormone level, and the other manifestations of Cockayne syndrome are still open to speculation. The premature thymic failure could be one element of the accelerated aging process characteristic of Cockayne syndrome. One then faces the unsolved problem of the cellular and molecular bases of thymic atrophy in normal aging (anomalies of DNA repair? Role of endocrine changes?...). Conversely, it is possible that the thymic anomaly is secondar to some of the clinical features of Cockayne syndrome. In any case, it is likely that the immunologic manifestations (infections, renal involvement) are linked to thymic failure. Although some controversial experiments have suggested that the thymus rnight control some endocrine glands, particularly the antihypophysis and gonads (7) it is unlikely that the thymic failure contributes to dwarfism.

In conclusion, we have reported a decrease of the serum level of thymic hormone in seven children with Cockayne syndrome. This abnormality is in keeping with the similar decline in thymic hormone level noted in normal aging. It is still difficult to assess whether this premature failure of the thymus function is part of the Cockayne syndrome, eventually secondary to a more fundamental disorder, or whether it represents one of the main factors in the etiopathogeneis of the disease, and is responsible for some of the clinical manifestations.

\section{REFERENCES AND NOTES}

1. Bach, J. F., Dardenne, M., Papiernik, M., Barois, A., Levasseur, P., and Le Brigand, H.: Evidence for a serum factor secreted by the human thymus. Lancet 2: 1056 (1972).

2. Bach, J. F., and Dardenne, M.: Demonstration and characterization of a circulating thymic hormone. Immunology, 25: 353 (1973).

3. Bach, J. F., Dardenne, M., Pleau, J. M., and Bach, M. A.: Isolation characterization and biological activity of a circulating thymic hormone in the mouse and in the human. Ann. N.Y. Acad. Sci., 249: 186 (1975).

4. Bach, M. A., and Beaurain, G.: Respective influence of extrinsic and intrinsic factor on the age-related decrease of thymic secretion. J. Immunol., 122: 2505 (1979).

5. Cartier, $P$., and Hamet, M.: Dosage de l'activité adénosine désaminasique dans les érythrocytes et les lymphocytes humains. Clin. Med. Acta, 71: 429 (1976).

6. Cockayne, E. A.: Dwarfism with retinal atrophy and deafness. Arch. Dis. Child. 11: 1 (1936).

7. Fabris, N.: Hormones and aging. In: T. Makinodan, E. Munnis: Immunology and Aging. pp. 79-82 (Plenum Medical Book Co., New York, 1977).

8. Fujimoto, W. Y., Greene, M. L., and Seegmiller, J. E.: Cockayne's syndrome. J. Pediatr., 75: 881 (1969).

9. Lafforet, D., and Dupuy, J. M.: Photosensibilité et réparation de l'adn, possibilité d'une parenté nosologique entre xeroderma pigmentosum et syndrome de Cockayne. Arch. Franç. Pédiatr., 35 (Suppl): 65 (1978).

10. Ohno, T., and Hirooka, M.: Renal lesions in Cockayne syndrome. J. Exp. Med., 89: 151 (1966).

11. Pincus, T., Schur, P. H., Rose, J. A., Decker, J. L., and Talal, N.: Measurement of serum DNA-binding activity in SLE. N. Engl. J. Med., 281: 701 (1969).

12. Riggs, W., and Seifert, J.: Cockayne's syndrome, roentgen findings. Am. J. Roentgenol. Radium Therapy Nuclear Med., 116: 623 (1972).

13. Srivastava, R. V., Gupta, P. C., Mayekar, G., and Roy, S.: Cockayne syndrome in two sisters. Acta Pediatr. Scand. 63: 461 (1974).

14. Sugarman, G. I., Landing, B. H., and Reed, W. B.: Cockayne syndrome: clinical study of two patients and neuropathological findings in one. Clin. Pediatr., 16: 225 (1977).

15. The authors thank Drs. Beauvais and Graveleau, as well as Professors Job and Gallet, who kindly allowed us to study their patients.

16. Requests for reprints should be addressed to: Dr. A. Bensman, Hôpital Trousseau 26. Avenue du Dr. A. Netter, 75012 Paris, France.

17. Informed consent was obtained from the parents for blood samples for immunological studies.

18. Informed consent was obtained from the parents to release and publish the photograph of one subject.

19. Received for publication July 15, 1980.

20. Accepted for publication April 22, 1981. 